\title{
PSYCHIATRIC DISORDERS IN MULTIPLE SCLEROSIS PATIENTS
}

\author{
Mirella Martins Fazzito', Sérgio Semeraro Jordy', Charles Peter Tilbery ${ }^{2}$
}

\begin{abstract}
Multiple sclerosis (MS) is a demyelinating disease showing variable clinical presentation. Optic neuritis is the most common symptom, followed by motor and sensitive manifestations. It is known that this disease may be related to several psychiatric disorders, especially depression. In this study we will discribe 5 cases of MS patients harboring psychiatric disorder related or unchained by the disease itself.
\end{abstract}

KEY WORDS: multiple sclerosis, psychiatric disorders, psychosis.

\begin{abstract}
Transtornos psiquiátricos em pacientes com esclerose múltipla
Resumo - Esclerose múltipla é uma doença desmielinizante com variadas apresentações clínicas. Neurite óptica e manifestações motoras e sensitivas são as mais frequentemente observadas. É conhecido que a doença pode ser associada a vários transtornos psiquiátricos, sobretudo depressão. Neste estudo são descritos 5 casos de pacientes com esclerose múltipla com transtornos psiquiátricos relacionados ou associados a própria patologia.
\end{abstract}

PALAVRAS-CHAVE: esclerose múltipla, transtornos psiquiátricos, psicose.

Multiple sclerosis (MS) is a demyelinating, inflammatory, autoimmune, neurodegenerative disease which attacks individuals between 20 and 40 years old, mainly female (3:1) and caucasians. The clinical presentation is variable with optic neuritis prevailing, besides motor and sensitive manifestations ${ }^{1,2}$. MS may be related to several psychiatric disorders which disturb mainly mood, behaviour and personality. Among those disorders, depression is the most frequently related ${ }^{3}$. Psychiatric symptoms are commonly observed during disease evolution but they are unusual as first symptoms and we estimate their occurrence at $1 \%$ of cases approximately. In many cases, MS is wrongly diagnosed as pure psychiatric disorder ${ }^{4}$.

We present patients who started their MS clinical presentation with psychiatric disorder or have developed it during MS follow-up. Due to uncommon cases of psychosis related to MS we will describe and discuss 5 cases of patients from Centro de Atendimento e Tratamento da Esclerose Múltipla (CATEM), at Santa Casa de Misericórdia de São Paulo who showed psychiatric disorders as MS clinical manifestation.
Our study was approved by Santa Casa Ethical Commission $n$ \% 0037/08, and had the agreement of all patients cited.

\section{CASES}

Case 1

A 58 years old, male, married, born and living in São Paulo.

Patient with preceding hypertension, taking enalapril and atenolol, started behavior change 4 years ago, characterized by hypersexuality, coprolalia, lack of inhibition and delusions, with progressive worsening. He began to invite strangers home. His family does not present any preceding psychiatric disorder or similar clinical presentation. He had normal clinical examination and neurological examination indicating short steps gait with face axial jerks. On psychiatric examination he was diagnosed harboring DSM-IV classification 293.81.

Further testing- Magnetic resonance image (MRI) (March 2006) with demyelinating lesions in periventricular location and corpus callosum (Fig 1). Cervical cord MRI (March, 2006) with demyelinating lesions. Cerebrospinal fluid: 2 cells, 30 red blood cells, $52 \%$ lymphocytes, $48 \%$ monocytes, $0 \%$ neutrophils, 63 protein

CATEM - Centro de Atendimento e Tratamento da Esclerose Múltipla, Santa Casa de Misericórdia de São Paulo, São Paulo SP, Brazil: 'Neurologista CATEM; ${ }^{2}$ Professor de Neurologia FCMSCSP e Chefe do CATEM. 


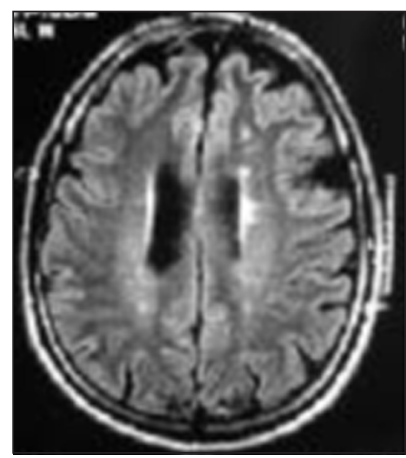

Fig 1. Case 1. MRI axial FLAIR sequence. Periventricular lesions and at corpus callosum.

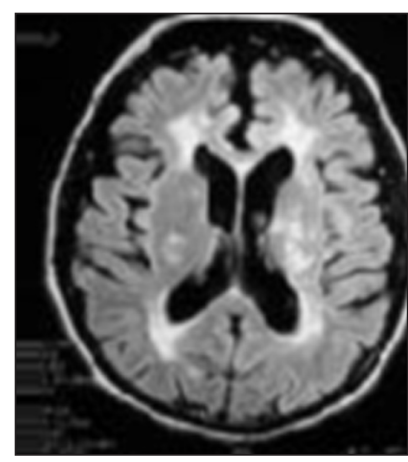

Fig 2. Case 2. MRI axial FLAIR sequence. Lesions at semioval center and corpus callosum.

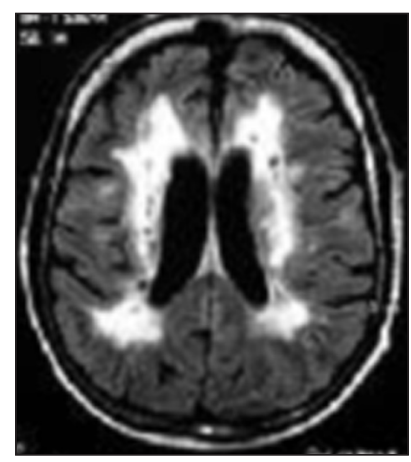

Fig 3. Case 3. MRI axial FLAIR sequence. Periventricular lesion and at corpus callosum.

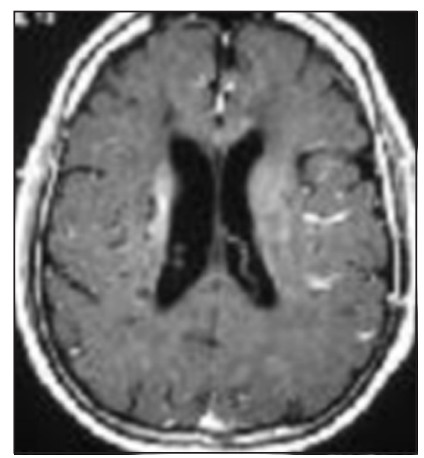

Fig 4. Case 4. MRI axial FLAIR sequence. Periventricular demyelinating lesions.

and 59 glucose. Positive oligoclonal bands. TSH: 3.75, free T4: 11.4, VDRL negative, B12 vitamin: 342.

MS was diagnosed after those further tests and pulsotherapy with methylprednisolone was started, leading to partial improvement of the clinical presentation.

\section{Case 2}

A 45 years old, female, single, born in Resende, living in São Paulo since 5 years ago. In 1997, patient started clinical presentation of paresthesias in inferior limbs during 15 days with spontaneous improvement. In 1998, she presented the same symptoms associated with motor incoordination and impaired vision. By that time she underwent a MRI which showed lesions compatible with MS and cerebrospinal fluid tested positive for oligoclonal bands. She started treatment with $\beta$-interferona la until 1999 and quit the treatment due to adverse effects.

Still in 1998 she had an outbreak with paresthesias in V3 location and, in 1999, she manifested psychotic clinical presentation with auto and heteroagressivity, remarkable change in behavior, and a persecutory delusion. At this time, on psychiatric evaluation, she was diagnosed DSM-IV 293.81. She started risperidone $0.5 \mathrm{mg}$ twice a day, with resulted in control of clinical presentation. She denies preceding psychiatric disorder or similar clinical presentation in her family.

Since 97, she has showed clinical and neurological examination with no important alterations though there were some vestiges of pyramidal liberation.

Further testing - MRI (2005): demyelinating lesions in periventricular location, semioval centers and right medium cerebellar peduncles (Fig 2).

\section{Case 3}

A 45 years old, male, married, born and living in São Paulo. Four years ago, patient started clinical presentation of left hemiparesthesias followed 3 months by right paresthesias. In 2004, he presented paraparesis, underwent plasmapheresis with partial improvement of clinical presentation, deambulating with cane.

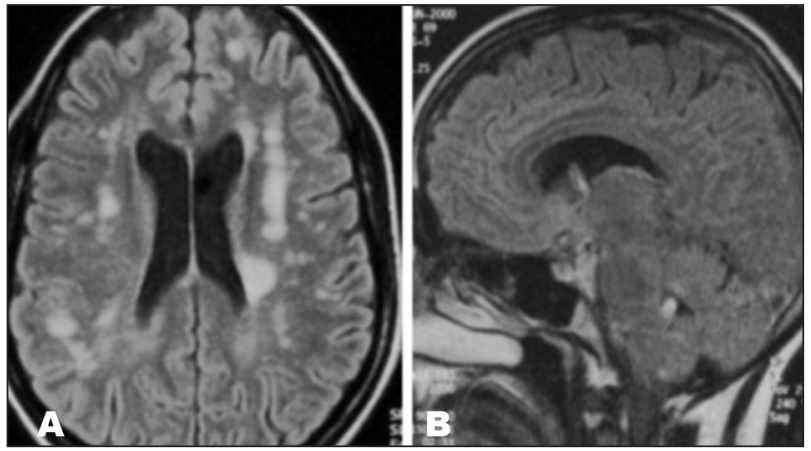

Fig 5. MRI axial [A] and sagital [B] FLAIR sequence. Diffuse demyelinating lesions.

Still in 2004, he showed behavior change, with psychomotor agitation, heteroagressivity and hypersomnia. He tried to commit suicide and kept depressive and discouraged since that outbreak time. At that time a psychiatrist diagnosed him harboring DSMIV 296.25. He was submitted to pulsotherapy with methilprednisolone during 3 days, followed by long-term treatment with haloperidol and amitriptyline, having controlled the psychotic and depressive symptoms. He denies preceding psychiatric disorder or similar clinical presentation in his family.

Clinical examination was normal. On neurological examination, there was mild monoparesis in left leg, global hyperreflexia with clonus, bilateral Hoffman and Babinski, and tetraspasticity. No alteration in other exams.

Further testing - MRI (April 2005): demyelinating lesions in periventricular location, corpus callosum (Fig 3). Cerebrospinal fluid (April 2005): 1 cell, 0 red blood cells, 93\% lymphocytes, $7 \%$ reticulomonocytes, 30 protein, 53 glucose. Positive oligloclonal bands.

\section{Case 4}

A 38 years old, male, married, born and living in São Paulo. In 1996, patient presented paresis of right leg, paresthesias in right foot and progressive worsening. He was hospitalized by that time 
and had MS diagnosed. MRI showed marked demyelinating lesions in periventricular location and left cerebellum. He started treatment with $\beta$-interferona 1a. In 1999, he had a psychotic outbreak with aggressiveness and behavior change, accompanied by psychomotor agitation, delusions, religious thoughts and insomnia, all compatible with DSM-IV 293.81 diagnosis. He underwent pulsotherapy with ciclofosfamide and had improvement in clinical presentation. He is now with no specific treatment because he refuses medication. He also denies preceding psychiatric disorder or similar clinical presentation in his family.

He shows normal clinical examination. On neurological examination, was seen repetitive speech, muscle strenght II-III in right inferior limb, IV in right superior limb, hyperactive reflexes in inferior limbs, bilateral Babinski. Negative others tests.

Further testing - MRI (July 2000): demyelinating lesions in periventricular location, bilateral semioval centers, and corpus callosum (Fig 4).

\section{Case 5}

A 47 years old, female, married, born and living in São Paulo. Patient says she started depressive clinical presentation 1 year ago, with insomnia, fatigue and social phobia. She was diagnosed DSM-IV 300.4 having a psychiatrist administered risperidone, valproic acid and escitalopram. During the evolution she complained left hemiparesthesias. In this period of time MS was diagnosed based in MRI alterations. She started pulsotherapy with methilprednisolone with whole remission of clinical presentation.

Clinical and neurological examinations are so far normal.

Further testing - Cerebrospinal fluid: 1 cell, 3 red blood cells, 23 protein, 60 glucose. Positive oligoclonal bands. TSH: 2.39, free T4: 11.4, VDRL negative (CSF and blood). Evocated visual potencial (May, 2007): no alteration. MRI (March and May 2007): demyelinating lesions (Fig 5).

\section{DISCUSSION}

MS may associate with several psychiatric disorders, attacking mainly mood, behavior, personality and cognition which make diagnosis difficult, especially at the beginning of disease ${ }^{3}$. In 1992, during the MS International Conference there was a consensus that MS patients are more vulnerable to psychiatric disorders. Studies show that $2 / 3$ of patients present neuropsychiatric disorder during evolution, but most of them do not undergo specific treatment ${ }^{6}$. One of the reported patients was first diagnosed with pure psychiatric disorder, having MS diagnosis only 1 year after the first symptoms.

We believe that MS patients show psychiatric disorders secondary to demyelinating lesions at the temporal lobe, with no physiopathology fully known $n^{7,8}$. The temporal lobe functions are language, memory and emotion. Lesions at this brain location may cause hallucinations, mood and thought disorder, euphoria, irritabillity and cognitive deficit. This brain location is especially associated with psychiatric alteration ${ }^{7}$. In the reported cases, lesions attacked several brain locations, mainly periventricular and corpus callosum

In their study Diaz Olavarrieta and coworkers 9 revealed that depression attacks $79 \%$ of studied MS patients. Of these patients $40 \%$ showed agitation during disease evolution, $37 \%$ showed anxiety, 35\% irritability, 20\% apathy, $13 \%$ euphoria, $13 \%$ lack of inhibition and 10\% some kind of hallucination. Patten and coworkers ${ }^{10}$ revealed that MS patients stand a good chance of developing depression. In this study, 3 patients showed psychosis, one of them, lack of inhibition and euphoria, and another, depression and anxiety. An essential factor in MS patients is mood change, because it affects directly the life quality and is associated with higher suicide rate. Studies reveal that in MS there is a higher suicide rate when it is compared to other neurological diseases and general population. The most valuable predictors to suicide are alcohol abuse, social isolation and depression itself $f^{3,10}$. Most of psychiatric disorders observed in MS patients occur during disease evolution and many times characterize an outbreak. In some cases the manifestations may be recurring ${ }^{9}$. Only $1 \%$ of MS cases have psychiatric alteration as this neurological disorder first manifestation ${ }^{4,11}$. Among the 5 reported cases, 2 showed psychiatric manifestation as first symptom (depression and behavior change). The other 3 showed psychosis during disease evolution. One of them keep manifesting the psychiatric disorder.

Patients in MS outbreak are subjected to pulsotherapy with solumedrol in order to lessen inflammatory activity and cease symptoms. In the reported cases, all patients took corticosteroids but in a short-term way, incapable to unchain a psychotic break secondary to its use.

Depression is the most frequent psychiatric symptom. Up to $50 \%$ of MS patients harbor depression but many times it is sub-diagnosed. It may mimic some symptoms of the MS itself, such as fatigue, sleep alteration, disturbance in appetite and motiveless $\mathrm{cry}^{3,6,12,13}$. Among the reported patients, one started with depression and social phobia, being first treated as a pure psychiatric patient. As long as she did not have any improvement, an investigation was conducted and MS was diagnosed.

Studies cite the association between MS and psychosis, bipolar disorder and pseudobulbar syndrome, though they are less common ${ }^{12,13}$. In this study, 3 patients showed psychosis during disease evolution with aggressiveness and remarkable behavior alteration.

We conclude that the association between MS and psychosis is not frequent enough to be remembered in daily practice. However, it is important to recognize it soon, for early specific treatment and psychiatric followup either. 


\section{REFERENCES}

1. Tilbery CP. Esclerose múltipla no Brasil: aspectos clínicos e terapêuticos. In: Sanvito WL (Ed). São Paulo: Atheneu, 2005;5:57-70.

2. Gonzalez-Rosa JJ, Vazquez-Marrufo M, Vaquero E, et al. Diferential cognitive impairment for diverse forms of multiple sclerosis. BMC Neurosci 2006; 7:39-42

3. Feinstein A. Neuropsychiatric syndromes associated with multiple sclerosis. J Neurol 2007;254(Suppl 2):S73-S76.

4. Jongen PG. Psychiatric onset of multiple sclerosis. J Neurol Sci 2006; 245:59-62.

5. Skegg K, Corwin PA, Skegg DC. How often multiple sclerosis mistaken for a psyquiatric disorder. Psychol Med 1988;18:733-736.

6. Rodgers J, Bland R. Psyquiatric manifestations of multiple sclerosis: a review. Can J Psyquiatry 1996;41:441-445.

7. Gudiéne D, Burba B. Mental disorders and their relation to brain location: diagnostical problems. Med 2003;39:114-119.
8. Reiss JP, Sam D, Sareen J. Psychosis in multiple sclerosis associated with left temporal lobe lesions on serial MRI scans. J Clin Neurosci 2006;13:282-284

9. Diaz-Olavarrieta C, Cummings JL, Velazquez B, et al. Neuropychistric manifestations of multiple sclerosis. J Neuropsychiatric Clin Neurosci 1999;11:51-57.

10. Patten SB, Beck CA, Willians JVA, et al. Major depression in multiple sclerosis: a population-based perspective. Neurology 2003;61: 1524-1527.

11. Skegg K. Sclerosis presenting as a pure psychiatric disorder. Psychol Med 1993;23:909-914.

12. Reimer J, Aderhold V, Lambert M et al. Manifestation of multiple sclerosis with paranoid-hallucinatory psychosis. J Neurol 2006;253:531-532.

13. Patten SB, Svenson L, Metz LM. Psychotic disorders in MS: population-based evidence of an association. Neurology 2005;65: 1123-1125. 